\title{
Koala retroviruses: characterization and impact on the life of koalas
}

Joachim Denner ${ }^{1 *}$ and Paul R Young ${ }^{2^{*}}$

\begin{abstract}
Koala retroviruses (KoRV) have been isolated from wild and captive koalas in Australia as well as from koala populations held in zoos in other countries. They are members of the genus Gammaretrovirus, are most closely related to gibbon ape leukemia virus (GaLV), feline leukemia virus (FeLV) and porcine endogenous retrovirus (PERV) and are likely the result of a relatively recent trans-species transmission from rodents or bats. The first KoRV to be isolated, KoRV-A, is widely distributed in the koala population in both integrated endogenous and infectious exogenous forms with evidence from museum specimens older than 150 years, indicating a relatively long engagement with the koala population. More recently, additional subtypes of KoRV that are not endogenized have been identified based on sequence differences and host cell receptor specificity (KoRV-B and KoRV-J). A specific association with fatal lymphoma and leukemia has been recently suggested for KoRV-B. In addition, it has been proposed that the high viral loads found in many animals may lead to immunomodulation resulting in a higher incidence of diseases such as chlamydiosis. Although the molecular basis of this immunomodulation is still unclear, purified KoRV particles and a peptide corresponding to a highly conserved domain in the envelope protein have been shown to modulate cytokine expression in vitro, similar to that induced by other gammaretroviruses. While much is still to be learned, KoRV induced lymphoma/leukemia and opportunistic disease arising as a consequence of immunomodulation are likely to play an important role in the stability of koala populations both in the wild and in captivity.
\end{abstract}

Keywords: Gammaretroviruses, Koala retrovirus, Lymphoma, Immunodeficiency

\section{Review}

\section{Distribution of KoRVs}

When an increasing incidence of lymphoma and leukemia was recognized in koalas [1], the question was raised whether this may be associated with a retrovirus given similar disease consequences in mice (murine leukemia virus, MuLV) [2,3], cats (FeLV) [4,5], gibbon apes (gibbon ape leukemia virus, GaLV) [6], and humans (human $\mathrm{T}$ cell leukemia virus, HTLV) [7]. MuLV, FeLV and KoRV are gammaretroviruses, HTLV is a deltaretrovirus and they all belong to the subfamily Orthoretrovirinae of the family Retroviridae. Retroviruses use the viral enzyme reverse transcriptase to produce a double-stranded DNA copy of the genomic RNA, which is integrated into the genome of the target cell. This integrated form of the viral genome is referred to as a provirus. At present, three KoRVs have

\footnotetext{
* Correspondence: DennerJ@rki.de; p.young@uq.edu.au

${ }^{1}$ Robert Koch Institute, Berlin, Germany

${ }^{2}$ School of Chemistry \& Molecular Biosciences, University of Queensland, St.
} Lucia, Brisbane, Australia been described, KoRV-A, KoRV-B and KoRV-J [8-10]. The origin of the KoRVs is still unclear, with a high probability that they are the result of a trans-species transmission from rodents or bats, since closely related gammaretroviruses have been found in South Eastern Asian mice [11,12] and bats $[13,14]$. It is likely that KoRV-A and GaLV, an exogenous retrovirus inducing leukemia in gibbons and using the orthogolous receptor, the sodium-dependent phosphate transporter Pit-1, have the same origin [8]. Of note, the lentiviruses HIV-1 and HIV-2 are also the result of a transspecies transmission [15,16]. KoRV-B and KoRV-J have been shown to encode an envelope gene with an altered receptor binding domain (RBD) resulting in the use of an alternative receptor, the thiamine transport protein 1 (THTR1) $[9,10]$. KoRV-A has been isolated from koalas in Australia [8,17] and in Japanese [18,19] and German [20] zoos. Retrovirus particles have also been described in animals at the San Diego zoo in the USA [21]. KoRV-B was isolated from animals in the Los Angeles zoo but not from
C Biomed Central

(c) 2013 Denner and Young; licensee BioMed Central Ltd. This is an open access article distributed under the terms of the Creative Commons Attribution License (http://creativecommons.org/licenses/by/2.0), which permits unrestricted use, distribution, and reproduction in any medium, provided the original work is properly cited. 
those at the San Diego zoo [9]. KoRV subtypes with modifications to the RBD have also been found in animals from the Duisburg and Antwerpen zoos in Europe as well as from wild koalas in Australia (our unpublished data). KoRV-A sequences have also been found in preserved pelts from animals kept in museums around the world [22]. KoRV-J was first isolated from a koala held in the Kobe Municipal Oji Zoo [18]. Later, 51 animals reared in 9 different Japanese zoos were investigated using differential PCR. $68 \%$ of the koalas sourced from northern Australia were positive for KoRV-J, whereas none of the animals sourced from the state of Victoria in the south of Australia were positive for KoRV-J [10]. In a first study investigating the prevalence of KoRV-A in the wild in Australia, a high number of infected animals were found in the North, whereas some animals in the South, especially on Kangaroo island were found to be negative [23]. In a later study investigating a larger number of animals, 100\% of koalas in Queensland and New South Wales were again shown to be carrying the virus while $14.8 \%$ (24 from 162) of the animals on Kangaroo Island were found to be positive, suggesting recent spread of the virus in this isolated koala population [24]. Subsequent field studies have indicated this figure may be as high as $30-35 \%$ (our unpublished data). The prevalence data must also be viewed in the context of wild koala populations that have undergone significant upheaval in the past. This is particularly the case for those populations in southern Australia that were hunted to near extinction in the late 1800s and early 1900s. Many of these areas were subsequently repopulated by the translocation of koalas from other localities but usually employing a relatively small number of animals, resulting in a drastic loss of genetic diversity [25].

\section{Endogenization of KoRV-A}

Retroviruses are divided into exogenous and endogenous forms. Exogenous retroviruses such as the human immunodeficiency virus HIV-1 are transmitted horizontally through infection of their specific somatic target cells $\left(\mathrm{CD} 4^{+} \mathrm{T}\right.$ lymphocytes in the case of HIV-1). However when a retrovirus infects germ cells, sperm cells or oocytes, the integrated DNA proviruses become a fixture of the genome of all cells of the developing organism. These are called endogenous retroviruses and will be transmitted vertically, inherited along with all other cellular genes [26]. While KoRV-B and KoRV-J appear to be exogenous retroviruses given that less than 1 copy per cell has been detected in tissues from infected animals, KoRV-A has been found in multiple proviral copies in the genome of every cell, including sperm cells of infected animals examined in northern Australia [23]. Its presence in sperm cells along with a host genome integration profile that appears identical in all tissues examined from each individual, indicates that it is endogenous in these populations [23]. However KoRV is not present in many of the koalas sampled across southern Australia [24] suggesting that it may currently be in the process of endogenizing the genome of this species. This unique situation presents an exciting opportunity to study the dynamic process of retroviral endogenization of a wild population in real-time.

\section{Biological properties of KoRV}

The KoRVs have the typical morphology, size (KoRV-A, Figure 1) and genome organization (Figure 2) of the gammaretroviruses. Like all retroviruses they encode a reverse transcriptase and structural proteins including the main core protein $\mathrm{p} 27 \mathrm{Gag}$ and the envelope proteins gp70 and p15E [20]. Most studies to date have focused on KoRV-A which has been shown to infect cells of different species (polytropic virus) in vitro including rat, human, feline and mink but not mouse cells $[10,19,20,27]$. It was shown to infect rats in vivo, but it remains unclear whether it is pathogenic in rats [20]. KoRV-B also infects a wide range of cells from different species including human [9]. Using pseudotyped KoRV-J, infection of human and cat cells was observed, but not of rat and mouse cells [10]. Infection in vitro does not automatically mean that these viruses can infect in vivo and give rise to a zoonosis. For example, when the host range of a closely related gammaretrovirus, PERV, was investigated, no infection was observed in humans, primates or other species when transplanting pig cells or injecting concentrated virus, despite the fact that cells of all species with the exception of mice could be infected in vitro (for review see [28]).

KoRV-A, -B and -J differ in the sequence of their RBD on the envelope protein gp70, which determines their differential receptor use. In addition, KoRV-B has four

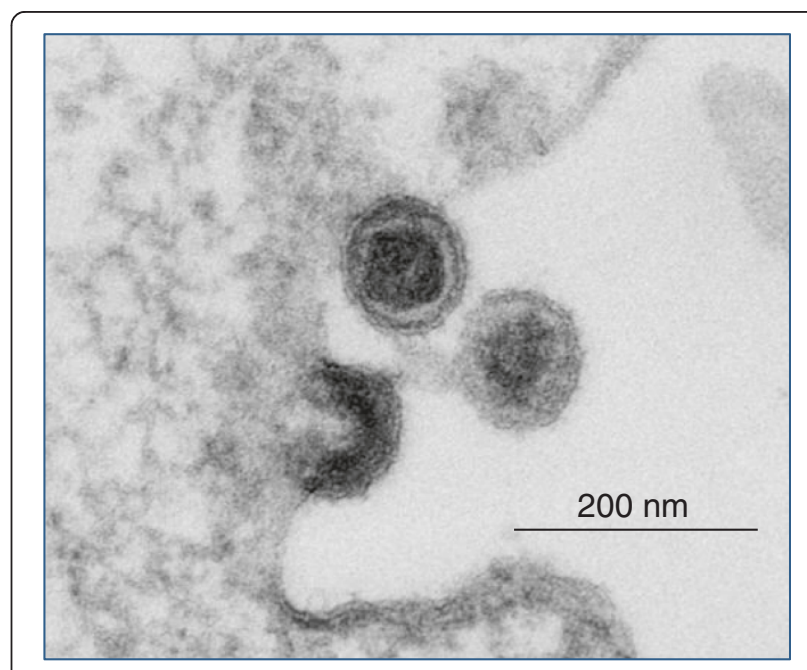

Figure 1 Electron microscopy of KoRV grown in human cells (Holland, Laue, Robert Koch Institute, Berlin). 


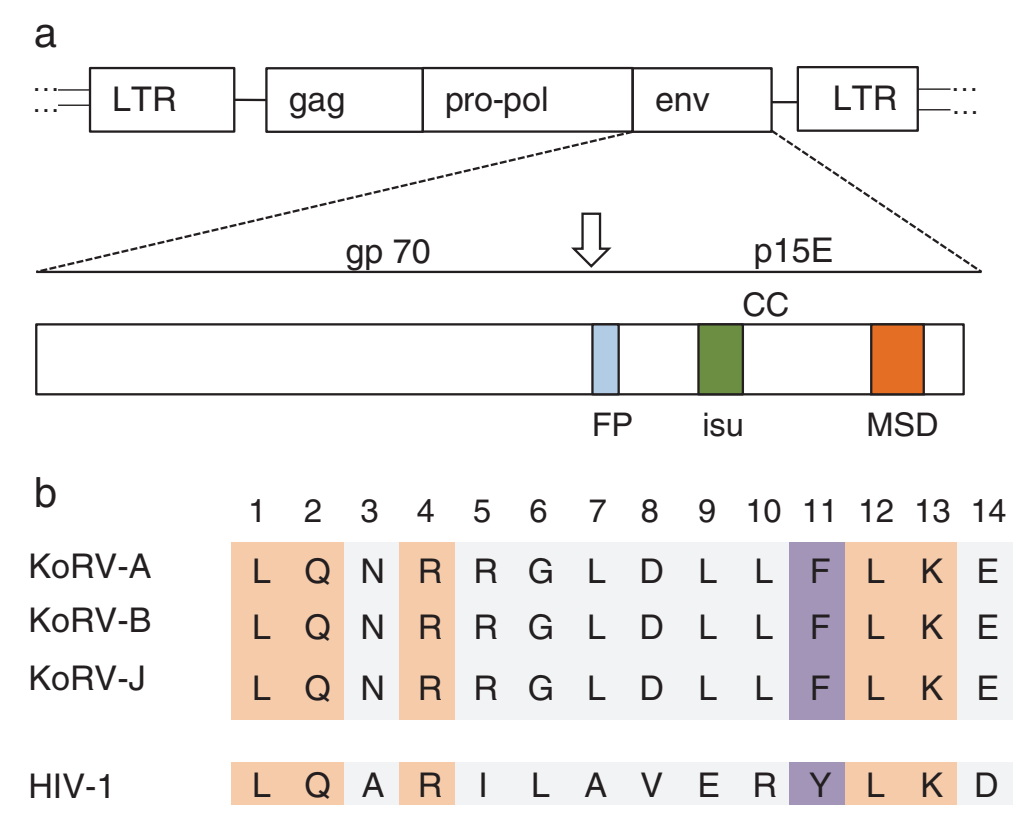

Figure 2 Schematic presentation of the integrated provirus of KoRV, structure of the envelope protein and sequence of the immunosuppressive domain. a, LTR, long terminal repeat; gag, group-specific antigen; pro-pol, protease-polymerase; env, envelope protein, FP, fusion peptide; isu, immunosuppressive domain; MSD, membrane spanning domain; CC, cysteine-cysteine loop. The arrow indicated the cleavage site between the surface ( $\mathrm{gp70}$ ) and the transmembrane ( $\mathrm{p} 15 \mathrm{E})$ envelope protein. $\mathbf{b}$, comparison of the sequence of the immunosuppressive domain of three KoRV subtypes and HIV-1. Identical amino acids are in orange, conservative exchanges in lilac.

repeats of a sequence in the $\mathrm{U} 3$ region of the long terminal repeat (LTR) that in KoRV-A is found as a single copy [9]. The U3 region influences gene expression with similar sequence multimerizations in the LTR of MuLV, FeLV and PERV [29-31]. Increased numbers of repeats correlate with increased replicative potential and hence higher virus titers. The sequence differences in the RBD of KoRV-A, KoRV-B and KoRV-J comprise substantial insertion/deletions suggesting that they may be the result of recombination between KoRV-A and another endogenous sequence yet to be identified.

\section{Diseases associated with a KoRV infection}

Retroviruses are known to induce tumors and/or immunodeficiency [3]. In some cases retroviruses are nonpathogenic, for example the foamy viruses [32,33], while others, such as MuLV [2,3], FeLV [4,5], GaLV [6], and HTLV [7] induce leukemia in the corresponding host. In addition, induced immunodeficiency often results in the onset of disease associated with opportunistic infections. Chlamydiosis is a major disease of koalas in both captivity and the wild [2,34], a disease also commonly associated with FIV (feline immunodeficiency virus) infections in cats [35] and HIV infections in humans [36]. In general, the diseases associated with FeLV infection in cats and KoRV infections in koalas are very similar (see list of Diseases reported in both FeLV-infected cats and KoRV-infected koalas and references $[1,4,5,8,17,21,34])$. Whereas only 5 to
$10 \%$ of FeLV-infected cats suffer from leukemia and lymphoma, more than $65 \%$ of them die from opportunistic infection based on an underlying immunodeficiency $[4,5]$.

Diseases reported in both FeLV-infected cats and KoRV-infected koalas
Lymphoma
Leukaemia
Anemia
Mesothelioma
Craniofacial tumors
Chlamydiosis
Rhinitis/Pneumonia
Stomatitis
Gingivitis
Crytococcosis
Toxoplasmosis

It is important to note that the virus load in the blood of KoRV positive koalas can be extremely high, reaching $>10^{9}$ genome equivalents $/ \mathrm{ml}$ in some animals [37]. Virus load has been found to correlate with disease progression, a correlation typical for other retrovirus infections [38]. The higher the virus load the higher the probability of insertional mutagenesis, one possible reason for tumor induction. It will also be important to learn whether particular KoRV subtypes are more associated with tumor development than others. Preliminary evidence suggests such an 
association for KoRV-B [9]. In addition, the higher the virus load, the higher the levels of the immunomodulating transmembrane envelope (TM) protein $\mathrm{p} 15 \mathrm{E}$, implicated as a key mediator of immunodeficiency (see below).

\section{Does KoRV induce immunodeficiency?}

Retroviruses are well known to induce immunodeficiency [3-5,39-42] and it is interesting to note that FeLV-infected cats as well as HIV-1-infected humans are characterized by a decrease in the number of $\mathrm{CD} 4^{+}$cells [43]. At present it is unknown whether KoRV infection alters the equivalent $\mathrm{CD} 4^{+}$cell count of infected koalas or indeed any other immunological marker. Immunological studies in koalas have been challenging given the absence of readily available reagents, however this is rapidly changing and the next few years should see a wealth of immunological measurements appearing in the literature.

The molecular mechanisms by which retroviruses induce immunodeficiency are still not completely understood. But there is accumulating evidence that the viral transmembrane (TM) protein, p15E, of all gammaretroviruses including KoRV is involved. All retroviral TM proteins contain a highly conserved sequence, referred to as the immunosuppressive (isu) domain (Figure 2). Viral particles and recombinant or native viral TM proteins of HIV-1 [44-47], human endogenous retrovirus HERV-K [48], PERV [40,49] and KoRV [20] have been shown to inhibit lymphocyte activation by mitogens and modulate cytokine expression in peripheral blood mononuclear cells (PBMCs). Single mutations in the isu domain of HIV-1 gp41 abrogated the immunosuppressive activity of the molecule and immunization with the mutated gp41 resulted in better antibody responses when compared with wild-type gp41 immunization [47]. The interleukins IL-10 and IL-6 were shown to be elevated and molecules involved in innate immunity were downregulated. Synthetic peptides corresponding to the isu domains were able to inhibit lymphocyte activation and to modulate gene expression in the same manner as the TM protein and whole viruses [50-53].

Retroviral TM proteins have also been shown to be immunosuppressive in vivo. Transformed cells that do not naturally develop tumors when injected into immunocompetent mice but do form tumors in immunocompromized mice, could be converted into tumor forming cells even in immunocompetent mice when TM proteins were expressed on their surface [41,42,54-56]. The expressed TM proteins not only prevented rejection of the transplanted cells, but also inhibited the humoral immune response as well as NK and $\mathrm{CD}^{+}$cells in the recipient animal $[56,57]$. The sequence of the isu domain is identical in all KoRV subtypes so far sequenced (Figure 2) and it would be surprising if the high viral loads carried by KoRV positive koalas throughout their lives did not have some impact on immune function.

\section{Impact on the life of koalas}

As noted above, many gammaretroviruses are known to cause neoplastic and immunosuppressive diseases in their respective hosts [2-5]. The fact that koalas suffering from lymphoma/leukemia have been shown to have higher levels of circulating KoRV viraemia [37] and that koalas also suffer from an unusually high incidence of chlamydiosis, a disease associated with immunosuppression induced by gammaretroviruses in other species [35,36], suggests that KoRV is no exception. These consequences of higher levels of KoRV load are most likely the result of an increase in the probability of mutational insertion and/or recombination for the induction of tumors and increased immunodeficiency. Therefore it is not surprising that populations with low levels of KoRV appear to have a correspondingly lower incidence of diseases than those with higher viral loads [37]. Although there is still no direct causal evidence for KoRV induced hematopoetic neoplasia and immunosuppression, the data published to date and comparison with other retroviral infections including HIV-1 strengthen the case for an association between KoRV and disease in koalas.

There are many challenges to the life of a koala in the wild. With an ever-expanding human population, many koala populations live in close urban association. Consequent ongoing habitat destruction, construction of roads that transect koala habitats, and attacks from domestic pets such as dogs pose an ever-increasing threat to population stability. However disease poses an additional and significant threat to koalas. Of particular concern are the increasing rates of KoRV infection seen in some populations $[23,24]$ suggesting that all animals may ultimately become infected. If the virus becomes endogenous in all animals this process is irreversible and the virus will be transmitted to all subsequent generations.

\section{Strategies for preventing infection and disease}

To prevent the further spread of KoRV in the koala population several strategies are potentially available; (i) The isolation or quarantine of uninfected koalas to prevent contact with infected animals. However this would only be possible for some groups of southern koala populations, since all populations in the north are already carrying the virus. (ii) Antiretroviral drug treatment for infected koalas. However the number of such drugs available for gammaretroviruses is limited. Susceptibility in vitro has been shown for the triphosphorylated nucleoside analog of zidovudine (AZT), ddGTP and to a lesser extent to ddTTP but almost no susceptibility to the non-nucleoside RT inhibitors was observed when activity against the related PERV was tested [58,59]. Even if a suitable anti-retroviral could be identified, treatment of koalas in captivity may be possible but the logistics would likely mean little or no impact on wild koala 
populations. (iii) Perhaps one of the most likely intervention strategies could be opportunistic vaccination. Thousands of animals are taken into care each year throughout Australia and then released back into the wild. These could be vaccinated while in care. In contrast to HIV-1, where all attempts to generate an effective vaccine have failed, protecting vaccines against gammaretroviruses have been successfully generated. The best example is FeLV where commercial vaccines exist which protect cats from virus replication and disease, however not from infection [43,60]. Better immunization strategies and antigens may lead to complete protection from infection. In addition to the vaccines against FeLV, experimental vaccines have been developed for MuLV. These approaches have included killed virus [61], subunit vaccines [62,63], and live attenuated viruses $[64,65]$. Immunization with the TM proteins of PERV [66-68], FeLV [60,69,70] and KoRV [20 and unpublished data] induce effective neutralizing antibodies mainly targeting epitopes in the membrane proximal external region (MPER) of the TM protein. When immunizing with a combination of the TM protein and the surface envelope protein (SU) gp70 of FeLV [71,72] and PERV [71,73], higher titers of neutralizing antibodies were induced. In the case of FeLV it was shown that these vaccinations protected cats from infection in vivo [60].

\section{Outlook}

Based on immunization experiments with gammaretroviruses closely related to KoRV, a similar effort to induce neutralizing antibodies against KoRV should be undertaken. Prevention of infection with KoRV (preventive vaccination) or decreasing the virus load (therapeutic treatment) in already infected animals could prevent or reduce KoRV-induced immunomodulation and therefore also protect animals from infection with chlamydia and other opportunistic infections. While this approach could offer significant additional management options for koalas in captivity, the challenge would be in the effective delivery of such a vaccine to a wild population dispersed over a broad geographic range.

\section{Conclusion}

The spread of a growing number of newly recognized KoRV genotypes in both wild and captive koalas has the potential to significantly impact the health of many koala populations. The long-term consequences to the species of these endogenizing elements are currently unknown. Koalas may eventually evolve and adapt to this genomic intruder, just as many other vertebrates, including humans have accommodated the array of retroviral elements that make up their genomes. However in the meantime, this relatively new and ongoing engagement between a group of retroviruses and their host is resulting in the appearance in the koala population of the same spectrum of diseases typically associated with many exogenous retroviral infections. While there are significant, and perhaps insurmountable logistical challenges in proposing any intervention strategies for many wild koala populations, this may be an option for koalas in captivity and some selected isolated wild koala populations. Both prevention and treatment strategies could be employed. An effective vaccine or therapeutic intervention would reduce virus load which in turn would likely reduce the induction of lymphoma/leukemia and the number and severity of opportunistic diseases arising as a consequence of immunomodulation. A reduction in virus load is also likely to reduce the probability of virus transmission. As for many other retrovirus examples, a preventive vaccine could be the best way to prevent further spread of the virus infection. Regardless of whether any of these strategies for control are feasible, the ongoing process of retroviral endogenization of the koala genome presents, for the first time an ideal opportunity to study this process in a wild population in real-time.

\section{Competing interests}

The authors declare that they have no competing interests.

\section{Authors' contribution}

Both authors contributed equally to this review. Both authors read and approved the final manuscript.

\section{Acknowledgement}

The authors thank all members of their laboratories for support and fruitful discussions. PY acknowledges the support of the Australian Research Council.

Received: 8 August 2013 Accepted: 7 October 2013

Published: 23 October 2013

\section{References}

1. Booth RJ, Blanshard WH: Diseases of koalas. In Zoo and wild animal medicine. Edited by Miller ME, Miller RE. Philadelphia: W.B. Saunders; 1999:321-333.

2. Moloney JB: The rodent leukemias: virus-induced murine leukemias. Annu Rev Med 1964, 15:383-392.

3. Rosenberg N, Jolicoeur P: Retroviral pathogenesis. In Retroviruses. Edited by Coffin JM, Hughes SH, Varmus HE. Cold Spring Harbor (NY): Cold Spring Harbor Laboratory Press; 1997.

4. Hardy WD: Feline retroviruses. In Advances in viral oncology. vol. 5th edition. Edited by Klein G. New York: Raven; 1985:1-34.

5. Hardy WD: Feline oncoretroviruses. In The retroviridae. vol. 2nd edition. Edited by Levy JA. New York: Plenum Press; 1993:109-180.

6. Gallo RC, Gallagher RE, Wong-Staal F, Aoki T, Markham PD, Schetters H, Ruscetti F, Valerio M, Walling MJ, O'Keeffe RT, Saxinger WC, Smith RG, Gillespie DH, Reitz MS Jr: Isolation and tissue distribution of type-C virus and viral components from a gibbon ape (Hylobates lar) with lymphocytic leukemia. Virol 1978, 84(2):359-373.

7. Kannian P, Green PL: Human T lymphotropic virus type 1 (HTLV-1): molecular biology and oncogenesis. Viruses 2010, 2(9):2037-2077.

8. Hanger JJ, Bromham LD, McKee JJ, O'Brien TM, Robinson WF: The nucleotide sequence of koala (phascolarctos cinereus) retrovirus: a novel type $C$ endogenous virus related to gibbon ape leukemia virus. J Virol 2000, 74:4264-4272. 
9. Xu W, Stadler CK, Gorman K, Jensen N, Kim D, Zheng H, Tang S, Switzer WM, Pye GW, Eiden MV: An exogenous retrovirus isolated from koalas with malignant neoplasias in a US zoo. Proc Natl Acad Sci U S A 2013, 110(28):11547-11552.

10. Shojima T, Yoshikawa R, Hoshino S, Shimode S, Nakagawa S, Ohata T, Nakaoka R, Miyazawa T: Identification of a novel subgroup of koala retrovirus from Koalas in Japanese zoos. J Virol 2013. Epub ahead of print.

11. Martin J, Herniou E, Cook J, O'Neill RW, Tristem M: Interclass transmission and phyletic host tracking in murine leukemia virus-related retroviruses. J Virol 1999, 73:2442-2449.

12. Lieber MM: Isolation from the Asian mouse Mus caroli of an endogenous type $C$ virus related to infectious primate type $C$ viruses. Proc Natl Acad Sci USA 1975, 72:2315-2319.

13. Cui J, Tachedjian G, Tachedjian M, Holmes EC, Zhang S, Wang LF: Identification of diverse groups of endogenous gammaretroviruses in mega- and microbats. J Gen Virol 2012, 93(Pt 9):2037-2045

14. Cui J, Tachedjian M, Wang L, Tachedjian G, Wang LF, Zhang S: Discovery of retroviral homologs in bats: implications for the origin of mammalian gammaretroviruses. J Virol 2012, 86(8):4288-4293.

15. Gao F: Genetic diversity of human immunodeficiency virus type 2: evidence for distinct sequence subtypes with differences in virus biology. J Virol 1994, 68:7433-7447.

16. Gao F: Origin of HIV-1 in the chimpanzee Pan troglodytes troglodytes. Nature 1999, 397:436-441.

17. Canfield PJ, Sabine JM, Love DN: Virus particles associated with leukaemia in a koala. Aust Vet J 1988, 65(10):327-328.

18. Miyazawa T, Shojima T, Yoshikawa R, Ohata T: Isolation of koala retroviruses from koalas in Japan. J Vet Med Sci 2011, 73(1):65-70.

19. Shojima T, Hoshino S, Abe M, Yasuda J, Shogen H, Kobayashi T, Miyazawa T: Construction and characterization of an infectious molecular clone of koala retrovirus. J Virol 2013, 7(9):5081-5088.

20. Fiebig U, Hartmann MG, Bannert N, Kurth R, Denner J: Transspecies transmission of the endogenous koala retrovirus. J Virol 2006, 80(11):5651-5654.

21. Worley M, Rideout B, Shima A, Janssen D: Opportunistic infections, cancer and hematologic disorders associated with retrovirus infection in the koala (Phascolarctos cinereus). Proc Assoc Zoo Vet 1993, 33:181-182.

22. Ávila-Arcos MC, Ho SY, Ishida Y, Nikolaidis N, Tsangaras K, Hönig K, Medina R, Rasmussen M, Fordyce SL, Calvignac-Spencer S, Willerslev E, Gilbert MT, Helgen KM, Roca AL, Greenwood AD: One hundred twenty years of koala retrovirus evolution determined from museum skins. Mol Biol Evol 2013, 30(2):299-304

23. Tarlinton RE, Meers J, Young PR: Retroviral invasion of the koala genome. Nature 2006, 442(7098):79-81.

24. Simmons GS, Young PR, Hanger JJ, Jones K, Clarke D, McKee JJ, Meers J: Prevalence of koala retrovirus in geographically diverse populations in Australia. Aust Vet J 2012, 90(10):404-409.

25. Tarlinton R, Meers J, Young P: Biology and evolution of the endogenous koala retrovirus. Cell Mol Life Sci 2008, 65(21):3413-3421.

26. Denner J: Endogenous retroviruses. In Retroviruses: molecular biology, genomics and pathogenesis. Edited by Kurth R, Bannert N. Hethersett, Norwich: Caister Academic Press; 2010:35-69.

27. Oliveira NM, Farrell KB, Eiden MV: In vitro characterization of a koala retrovirus. J Virol 2006, 80(6):3104-3107.

28. Denner J, Tönjes RR: Infection barriers to successful xenotransplantation focusing on porcine endogenous retroviruses. Clin Microbiol Rev 2012, 25(2):318-343.

29. Denner J, Specke V, Thiesen U, Karlas A, Kurth R: Genetic alterations of the long terminal repeat of an ecotropic porcine endogenous retrovirus during passage in human cells. Virology 2003, 15(1):125-133. 314

30. DesGrosseillers $L$, Jolicoeur $P$ : The tandem direct repeats within the long terminal repeat of murine leukemia viruses are the primary determinant of their leukemogenic potential. J Virol 1984, 52:945-952.

31. Athas B, Choi S, Prabhu P, Lobelle-Rich L, Levy S: Genetic determinants of feline leukemia virus-induced multicentric lymphomas. Virology 1995, 214:431-438.

32. Linial M: Why aren't foamy viruses pathogenic? Trends Microbiol 2000, 8(6):284-289.

33. German AC, Harbour DA, Helps CR, Gruffydd-Jones TJ: Is feline foamy virus really apathogenic? Vet Immunol Immunopathol 2008, 123(1-2):114-118.

34. Brown AS, Girjes AA, Lavin MF, Timms P, Woolcock JB: Chlamydial disease in koalas. Aust Vet J 1987, 64:346-350
35. O'Dair HA, Hopper CD, Gruffydd-Jones TJ, Harbour DA, Waters L: Clinical aspects of Chlamydia psittaci infection in cats infected with feline immunodeficiency virus. Vet $\operatorname{Rec} 1994,134: 365-368$.

36. Contini C: Molecular identification and antibody testing of Chlamydophila pneumoniae in a subgroup of patients with HIV associated dementia complex. J Neuroimmunol 2003, 136:172-177.

37. Tarlinton R, Meers J, Hanger J, Young P: Real-time reverse transcriptase PCR for the endogenous koala retrovirus reveals an association between plasma viral load and neoplastic disease in koalas. J Gen Virol 2005, 86(Pt 3):783-787.

38. Mellors JW, Munoz A, Giorgi JV, Margolick JB, Tassoni CJ, Gupta P, Kingsley $L A$, Todd JA, Saah AJ, Detels R, Phair JP, Rinaldo CR Jr: Plasma viral load and CD4+ lymphocytes as prognostic markers of HIV-1 infection. Ann Intern Med 1997, 126(12):946-954

39. Oostendorp RA, Meijer CJ, Scheper RJ: Immunosuppression by retroviralenvelope-related proteins, and their role in non-retroviral human disease. Crit Rev Oncol Hematol 1993, 14:189-206.

40. Denner J: Immunosuppression by retroviruses: implications for xenotransplantation. Ann NY Acad Sci 1998, 862:75-86.

41. Mangeney M, de Parseval N, Thomas G, Heidmann T: The full-length envelope of an HERV-H human endogenous retrovirus has immunosuppressive properties. J Gen Virol 2001, 82:2515-2518.

42. Denner J: Immunosuppression by oncogenic retroviridae. In Immune modulation by infectious agents. Edited by Zschiesche W. Jena: Fischer Verlag; 1987:114-201.

43. Hofmann-Lehmann R, Holznagel E, Ossent P, Lutz H: Parameters of disease progression in long-term experimental feline retrovirus (feline immunodeficiency virus and feline leukemia virus) infections: hematology, clinical chemistry, and lymphocyte subsets. Clin Diagn Lab Immunol 1997, 4:33-42.

44. Speth C, Joebstl B, Barcova M, Dierich MP: HIV-1 envelope protein gp41 modulates expression of interleukin-10 and chemokine receptors on monocytes, astrocytes and neurones. AIDS 2000, 14(6):629-636.

45. Barcova M, Kacani L, Speth C, Dierich MP: gp41 envelope protein of human immunodeficiency virus induces interleukin (IL)-10 in monocytes, but not in $\mathrm{B}, \mathrm{T}$, or NK cells, leading to reduced IL-2 and interferongamma production. J Infect Dis 1998, 177(4):905-913.

46. Denner J, Eschricht M, Lauck M, Semaan M, Schlaermann P, Ryu H, Akyüz L: Modulation of cytokine release and gene expression by the immunosuppressive domain of gp41 of HIV-1. PLoS One 2013, 8(1):e55199.

47. Morozov VA, Morozov AV, Semaan M, Denner J: Single mutations in the transmembrane envelope protein abrogate the immunosuppressive property of HIV-1. Retrovirol 2012, 9:67.

48. Morozov VA, Dao Thi VL, Denner J: The transmembrane protein of the human endogenous retrovirus - $\mathrm{K}$ (HERV-K) modulates cytokine release and gene expression. Plos one 2013, 8(8):e70399.

49. Tacke SJ, Kurth R, Denner J: Porcine endogenous retroviruses inhibit human immune cell function: risk for xenotransplantation? Virology 2000, 268(1):87-93.

50. Cianciolo G, Copeland T, Oroszlan S, Snyderman R: Inhibition of lymphocyte proliferation by a synthetic peptide homologous to retroviral envelope proteins. Science 1985, 230:453-455.

51. Denner J, Norley S, Kurth R: The immunosuppressive peptide of HIV-1: functional domains and immune response in AIDS patients. Aids 1994, 8:1063-1072

52. Denner J, Persin C, Vogel T, Haustein D, Norley S, Kurth R: The immunosuppressive peptide of HIV-1 inhibits T and B lymphocyte stimulation. J Acquir Immune Defic Syndr Hum Retrov 1996, 12(5):442-450.

53. Ruegg C, Monell C, Strand M: Inhibition of lymphoproliferation by a synthetic peptide with sequence identity to gp41 of human immunodeficiency virus type 1. J Virol 1989, 63:3257-3260.

54. Mangeney $M$, Heidmann $\mathrm{T}$ : Tumor cells expressing a retroviral envelope escape immune rejection in vivo. Proc Natl Acad Sci U S A 1998, 8(25):14920-14925. 95

55. Blaise S, Mangeney M, Heidmann T: The envelope of Mason-Pfizer monkey virus has immunosuppressive properties. J Gen Virol 2001 82(Pt 7):1597-1600.

56. Schlecht-Louf G, Renard M, Mangeney M, Letzelter C, Richaud A, Ducos B, Bouallaga I, Heidmann T: Retroviral infection in vivo requires an immune escape virulence factor encrypted in the envelope protein of oncoretroviruses. Proc Natl Acad Sci U S A 2010, 107(8):3782-3787. 
57. Mangeney M, Renard M, Schlecht-Louf G, Bouallaga I, Heidmann O, Letzelter C, Richaud A, Ducos B, Heidmann T: Placental syncytins: genetic disjunction between the fusogenic and immunosuppressive activity of retroviral envelope proteins. Proc Natl Acad Sci U S A 2007, 104(51):20534-20539.

58. Wilhelm M, Fishman JA, Pontikis R, Aubertin AM, Wilhelm FX: Susceptibility of recombinant porcine endogenous retrovirus reverse transcriptase to nucleoside and non-nucleoside inhibitors. Cell Mol Life Sci 2002, 59(12):2184-2190.

59. Stephan O, Schwendemann J, Specke V, Tacke SJ, Boller K, Denner J: Porcine endogenous retroviruses (PERVs): generation of specific antibodies, development of an immunoperoxidase assay (IPA) and inhibition by AZT. Xenotransplant 2001, 8(4):310-316.

60. Langhammer S, Hübner J, Jarrett O, Kurth R, Denner J: Immunization with the transmembrane protein of a retrovirus, feline leukemia virus: absence of antigenemia following challenge. Antiviral Res 2011, 89(1):119-123.

61. Fink MA, Rauscher FJ: Immune reactions to a murine leukemia virus I. Induction of immunity to infection with virus in the natural host. J Natl Cancer Inst 1964, 32:1075-1082.

62. Hunsmann G: Subunit vaccines against exogenous retroviruses: overview and perspectives. Cancer Res 1985, 45:4691-4693.

63. Fischinger PJ, Schäfer W, Bolognesi DP: Neutralization of homologous and heterologous oncornaviruses by Antisera against the p15(E) and gp71 polypeptides of friend murine leukemia virus. Virology 1976, 71(1):169-184

64. Ruan KS, Lilly F: Approach to a retrovirus vaccine: immunization of mice against friend virus disease with a replication-defective friend murine leukemia virus. Proc Natl Acad Sci U S A 1992, 89(24):12202-12206.

65. Ruprecht RM, Hu Y, Liska V, Rasmussen R, Sharma P: Correlates of immune protection after vaccination with attenuated live murine leukemia virus. AIDS Res Hum Retrov 1996, 12(5):375-377.

66. Fiebig U, Stephan O, Kurth R, Denner J: Neutralizing antibodies against conserved domains of $\mathrm{p} 15 \mathrm{E}$ of porcine endogenous retroviruses: basis for a vaccine for xenotransplantation. Virology 2003, 307(2):406-413.

67. Kaulitz D, Fiebig U, Eschricht M, Wurzbacher C, Kurth R, Denner J: Generation of neutralising antibodies against porcine endogenous retroviruses (PERVs). Virology 2011, 411(1):78-86.

68. Waechter A, Eschricht M, Denner J: Neutralization of porcine endogenous retrovirus by antibodies against the membrane-proximal external region of the transmembrane envelope protein. J Gen Virol 2013, 94(Pt 3):643-651.

69. Langhammer S, Fiebig U, Kurth R, Denner J: Neutralising antibodies against the transmembrane protein of feline leukaemia virus (FeLV). Vaccine 2005, 23(25):3341-3348.

70. Langhammer S, Hübner J, Kurth R, Denner J: Antibodies neutralizing feline leukaemia virus (FeLV) in cats immunized with the transmembrane envelope protein p15E. Immunology 2006, 117(2):229-237.

71. Denner J: Immunising with the transmembrane envelope proteins of different retroviruses including HIV-1: a comparative study. Hum Vaccin Immunother 2012, 9(3):462-470.

72. Langhammer S, Fiebig U, Kurth R, Denner J: Increased neutralizing antibody response after simultaneous immunization with Leucogen and the feline leukemia virus transmembrane protein. Intervirol 2011, 54(2):78-86.

73. Denner J, Mihica D, Kaulitz D, Schmidt CM: Increased titers of neutralizing antibodies after immunization with both envelope proteins of the porcine endogenous retroviruses (PERVs). Virol J 2012, 9:260.

doi:10.1186/1742-4690-10-108

Cite this article as: Denner and Young: Koala retroviruses: characterization and impact on the life of koalas. Retrovirology 2013 10:108.

\section{Submit your next manuscript to BioMed Central and take full advantage of:}

- Convenient online submission

- Thorough peer review

- No space constraints or color figure charges

- Immediate publication on acceptance

- Inclusion in PubMed, CAS, Scopus and Google Scholar

- Research which is freely available for redistribution

Submit your manuscript at www.biomedcentral.com/submit
C Biomed Central 